\title{
ARQUIVO PESSOAL: FUNDO DOCUMENTAL NEUSA CARSON ${ }^{1}$
}

\section{PERSONAL ARCHIVES: NEUSA CARSON DOCUMENTAL FUND}

\author{
Carla Saldanha da Silva (UFSM) ${ }^{2}$ \\ Rosani Beatriz Pivetta da Silva (UFSM) ${ }^{3}$
}

Resumo: De modo geral, a pessoa mantém, sob sua custódia, documentos que, ao longo de sua vida, são produzidos ou recebidos, tendo assim o interesse particular de guarda. Os momentos vivenciados são testemunhados por documentos que, preservados e arranjados, podem servir como fontes de informação, pois neles está a trajetória de vida e a memória da pessoa física, formando seu arquivo pessoal. Os arquivos pessoais têm singularidades e especificidades diferentes dos arquivos institucionais, e isso também faz com que eles, muitas vezes, nos auxiliem no entendimento de outros arquivos. Assim, organizar um fundo documental de um arquivo pessoal requer do arquivista um trabalho de pesquisa que não se limita somente a teorias arquivísticas, mas conta com saberes advindos de outras áreas, como a História, Linguística, Paleografia e a própria área de atuação da pessoa produtora do acervo documental. A partir desse pensamento, foi desenvolvida uma política de arranjo e descrição de documentos para o Fundo Documental Neusa Carson. O projeto do Fundo Documental Neusa Carson teve origem por meio da doação, por seus familiares, de documentos que tratam da vida profissional e acadêmica da Prof. ${ }^{a}$ Dr. ${ }^{a}$ Neusa Martins Carson (1944-1987).

Palavras-chave: arquivos; fundo documental; arquivos pessoais; documentos.

Abstract: In general a person keeps under her custody documents that over the course of her life are produced or received, having, therefore, particular interest for safekeeping. The moments experienced are witnessed by documents that preserved and arranged, may serve as informational sources, for in them is the life trajectory and memory of the physical person, forming her personal archive. The personal archives have different singularities and specifications than institutional archives, which make them useful in the understanding of other files. Therefore, organizing a documental fund of a personal archive requires from the archivist a research work that does not limit itself at archival theories, but also requires studies in other areas as history, linguistics, paleography and the work area of the person who produced the documental fund. From this thought, a policy of arrangement and description of documents of the Neusa Carson Documental Fund was developed. The project of the Neusa Carson Documental Fund had its origin in the donation of documents by her relatives, documents related to the professional and academic life of Professor Doctor Neusa Martins Carson (1944-1987).

Key-words: archives; documental fund; personal archives; documents.

\footnotetext{
${ }^{1}$ Artigo produzido no âmbito do projeto Fundo Documental Neusa Carson, registrado no Gabinete de Projetos do Centro de Artes e Letras - GAP/CAL 031241, sob a coorientação da Prof. ${ }^{a}$ Dr. ${ }^{a}$ Simone de Mello de Oliveira.

2 Arquivista formada na Universidade Federal de Santa Maria e acadêmica do curso de História Licenciatura Plena e Bacharelado da Universidade Federal de Santa Maria. E-mail: carla.arquivologia@gmail.com

${ }^{3}$ Professora do Departamento de Documentação da Universidade Federal de Santa Maria. E-mail: rosanipivetta@ufsm.br
} 


\section{Introdução}

"Arquivos Pessoais, portanto, são conjuntos documentais, de origem privada, acumulados por pessoas físicas e que se relacionam de alguma forma às atividades desenvolvidas e aos interesses cultivados por essas pessoas, ao longo de suas de vidas" (Fundação Getúlio Vargas)4. O contato com fontes primárias, capazes de revelar atividades de uma pessoa física, é uma sensação única de transporte no tempo e na vida de personagens, pois traduzem uma história. A imersão nos arquivos pessoais de forma direta não só nos revela experiências vividas por esses atores, como também faz com que nos deparemos, aos poucos, com frações muito íntimas de suas histórias.

As informações contidas nesses acervos interessam como fonte de pesquisa e são dotadas de singularidade, uma vez que são produzidas por homens e mulheres, ao longo da vida, sem a finalidade de serem históricas e culturais, embora possam adquirir valores que lhes são inatos por testemunharem a memória de quem os acumulou ou produziu. Sendo assim, tanto os acervos pessoais quanto os arquivos institucionais devem receber tratamento arquivístico, para, assim, após a sua organização, garantir e possibilitar o acesso à documentação. Considerando esse processo, foi desenvolvido um trabalho de arranjo dos documentos que fazem parte do Fundo Documental Neusa Carson.

O projeto do Fundo Documental Neusa Carson teve origem na doação da documentação da vida profissional e acadêmica da Prof. ${ }^{a}$ Dr. ${ }^{a}$ Neusa Martins Carson, feita por seu filho Hugo Carson, em 20 de agosto de 2011. A doação foi realizada ao Laboratório Corpus - Laboratório de Fontes de Estudos da Linguagem, vinculado ao programa de Pós-Graduação em Letras, da Universidade Federal de Santa Maria, instituição de ensino essa na qual Neusa Carson foi professora. A partir desse ato, foi instituída uma política para organização de acervo documental, formando o Fundo Documental Neusa Carson.

Neusa Martins Carson nasceu em 27 de julho de 1944 e faleceu em 16 de dezembro de 1987. Sua formação escolar foi em Santa Maria, no Rio Grande do Sul. Em 1965, ingressou no curso de graduação em Letras (Base Inglês) da Faculdade de Filosofia, Ciências e Letras "Imaculada Conceição". Durante a graduação, participou de inúmeras atividades acadêmicas. Em 1966, foi aprovada no concurso público da Universidade Federal de Santa Maria para o cargo de escriturária e, no ano seguinte, foi designada chefe da seção de divulgação e propaganda. Em 1968, dá-se o início da sua carreira como professora universitária, ministrando a disciplina de Linguística no curso de Letras da UFSM.

${ }^{4}$ Fonte: $<$ http://cpdoc.fgv.br/acervo/arquivospessoais $>$. 
No ano de 1970, Neusa realizou seu mestrado nos Estados Unidos, cuja dissertação tem por título Bilingualism in Primary School Children. Após seu retorno ao Brasil, em 1972, Neusa foi designada ao cargo de Professor Assistente da UFSM. Sua formação profissional foi intensificada após mais uma estada nos Estados Unidos, entre os anos de 1974 e 1976, para desenvolver pesquisas e atividades acadêmicas em Ohio State University, onde obteve o título de Master of Philosophy com a monografia intitulada The Problem of Classification of South American, e, posteriormente, em Kansas University, para a realização do doutorado com a tese Phonology and Morpho-Syntax of Macuxi (Carib) (DIAS, 2012, p. 2). É a partir da tese que Neusa se dedica a estudar a descrição de línguas, mais precisamente com a descrição da língua Macuxi ${ }^{5}$, no Estado de Roraima. Durante todo esse período de pós-graduação, Neusa Carson fez várias publicações e prestou alguns assessoramentos como docente não só para outros cursos da UFSM como também para outras universidades.

Durante praticamente todo primeiro semestre do ano de 1985, a professora realizou seu pós-doutorado na Universidade de Berkeley, nos Estados Unidos. Durante esse período, viajou para países como a França, Inglaterra e Alemanha promovendo um ciclo de palestras a fim de expandir as pesquisas linguísticas que estava desenvolvendo. Ao longo dessa viagem, foi estreitando laços profissionais com vários pesquisadores, assim como fez no decorrer de sua carreira.

De acordo com o acervo doado, foi possível perceber que seu último trabalho teria sido realizado em agosto de 1987, quando a pesquisadora participou de um Seminário sobre Línguas Indígenas da Amazônia, nos Estados Unidos.

Com a doação da documentação, observamos o empenho e a dedicação que a professora Neusa Carson teve durante toda sua carreira, pois, dada a época, teve relevante atuação, mesmo com a escassez de recursos e a falta de estrutura para realizar as viagens de pesquisa, visto que as localidades onde se encontravam as tribos indígenas eram de difícil acesso. Mas, considerando o entusiasmo e também a atenção que ela tinha para com estas comunidades, esses fatores não foram obstáculos para o empreendimento de suas pesquisas.

\section{A organização do Fundo Documental Neusa Carson}

A documentação que compõe o fundo documental de Neusa Carson representa as funções e as atividades desempenhadas ao longo da carreira

\footnotetext{
${ }^{5}$ Macuxi é do troco linguístico Caribe, considerado uma língua do grupo leste-oeste da região guianense. Esse grupo se estende, além da Guiana Brasileira, para a Venezuela a oeste e para a Guyana (antiga Guiana Inglesa), Suriname e Guiana Francesa a leste (CARSON, 1983 apud DIAS, 2012, p. 2).
} 
acadêmica e profissional da professora. Podemos chamar de "fundo" o acervo doado devido às características da produção desses documentos:

Fundo documental é o conjunto de documentos produzidos e/ou acumulados por determinada entidade pública ou privada, pessoa ou família, no exercício de suas funções e atividades, guardando entre si relações orgânicas e que são preservados como prova ou testemunho legal e/ou cultural, não devendo ser mesclados a documentos de outro conjunto, gerado por outra instituição, mesmo que este, por qualquer razão, lhe seja afim (BELLOTTO, 2006, p. 128).

Esse fundo é denominado de fundo fechado, pois não haverá mais produção de documentos devido ao falecimento da pesquisadora. Mesmo assim, o referido fundo pode continuar a receber tais documentos, tendo em vista que, caso exista mais material, esse ainda poderá ser doado pela família, pelos amigos, entre outros. Nesse sentido, fundo fechado é:

[...] um conjunto de arquivos ao qual não se irão juntar mais documentos, como é o caso, por razões evidentes, do arquivo de uma personagem falecida. Compreende-se que o encerramento de um fundo remeta para atividades que já não geram documentos e não para os próprios documentos. Assim, pode acontecer que alguns documentos se juntem excepcionalmente ao fundo fechado da nossa personagem, se se descobrir, por exemplo, uma parte da sua correspondência. Isto nada tem a ver com um retomar das atividades da personagem, mas antes com a descoberta de documentos gerados quando o fundo ainda era aberto (ROUSSEAU; COUTURE, 1998, p. 92).

Por se tratar de um acervo constituído por uma documentação produzida pela pesquisadora e referente a atividades acadêmicas, isto é, documentos que têm um caráter tanto particular quanto público, pois revela fatos de instituições com as quais a professora Neusa teve contato, esses documentos, mesmo sendo produzidos em outras instituições, foram recebidos e fazem parte do acervo de Neusa Carson. Os arquivos pessoais possuem uma grande especificidade por terem como objeto e fonte desses conjuntos documentais a vida dos indivíduos, suas relações sociais e acadêmicas. Esses arquivos se diferem muito dos arquivos produzidos por uma instituição. Enquanto os documentos institucionais representam um conjunto homogêneo e necessário, resultado de uma atividade administrativa, os documentos pessoais podem ser produtos de uma intenção de perpetuar uma determinada imagem; portanto, fruto de uma seleção arbitrária, os quais se apresentam como agrupamento artificial e antinatural onde não é possível a objetividade (SANTOS, 2012).

Ao pensarmos o acervo pessoal da professora Neusa Carson, estamos também tratando de um conjunto de documentos valiosos para inúmeros tipos de pesquisa, como a relacionada à língua indígena, ao acesso às tribos indígena nas décadas de 70 e 80 , à ascensão acadêmica e profissional da mulher entre 
essas décadas no Brasil, ao investimento financeiro em pesquisas, etc. Com isso:

\begin{abstract}
Pode-se definir arquivo pessoal como o conjunto de papéis e material audiovisual ou icnográfico resultante da vida e da obra/atividades de estadistas, políticos, administradores, líderes de categorias profissionais, cientistas, escritores, artistas etc. Enfim, pessoas cuja maneira de pensar, agir, atuar e viver possa ter algum interesse para as pesquisas nas respectivas áreas onde desenvolveram suas atividades; ou ainda, pessoas detentoras de informações inéditas em seus documentos que, se divulgadas na comunidade científica e na sociedade civil, trarão fatos novos para as ciências, artes e a sociedade (BELLOTTO, 2006, p. 266).
\end{abstract}

Em nosso entender, esse é o caso dos documentos constituintes do Fundo Documental Neusa Carson, pelo fato de essa cientista ser uma pesquisadora à frente do seu tempo, protagonista de uma história a ser contada sobre a Linguística dos anos 70 e 80.

\title{
Metodologia de trabalho utilizada
}

fases:

A metodologia de organização do fundo documental foi planejada em $1^{a}$ fase: Separação dos documentos pelo gênero

O acervo é composto por documentos de três gêneros documentais diferentes: textuais, iconográficos e tridimensionais, "gênero documental é reunião de espécies documentais que se assemelham por seus caracteres essenciais, particularmente o suporte e o formato, e que exigem processamento técnico específico e, por vezes, mediação técnica para acesso" (DBTA, 2005, p. 99).

Essa fase possibilitou a realização da fase seguinte do processo de organização, a higienização.

$2^{\mathrm{a}}$ fase: Higienização

Nesta etapa, foi realizada a limpeza superficial dos documentos, utilizando-se uma trincha para tirar a poeira neles existente. Também, foram desamassados e deles retirados clipes e grampos de metais, para que, assim, fosse mantida a conservação do material.

O acervo estava conservado e por esse motivo não foi necessário fazer intervenções de restauração. Com isso, percebemos a atenção que a pesquisadora teve com seus documentos, pelo cuidado e pela organização a 
partir da qual eles se encontravam, bem como a dedicação da família, pela manutenção e preservação dos referidos documentos.

$3^{a}$ fase: Identificação dos documentos

Utilizamos a definição técnica disponível no Dicionário Brasileiro de Terminologia Arquivística (2005) para definir inicialmente esta etapa. "Identificação é o processo de reconhecimento, sistematização e registro de informações sobre arquivos com vistas ao seu controle físico e/ou intelectual" (DBTA, 2005, p. 104).

Cada documento foi colocado entre uma folha dupla de rascunho (folha almaço), na qual foram realizadas anotações, a lápis, que são informações básicas de identificação, como: tipologia, assunto, datas, nomes, etc. Junto com a identificação, foram numerados todos os documentos para possibilitar a organização de uma listagem de controle da documentação.

$\mathrm{O}$ acervo contém documentos em outras línguas, como o inglês, devido ao extenso período em que a Prof. ${ }^{a}$ Neusa viveu nos Estados Unidos realizando a sua pós-graduação, e também relativos às correspondências trocadas com outros pesquisadores. Dessa documentação, foi realizada a tradução por uma equipe constituída no interior do projeto, o Polo Inglês, coordenado por Daniela do $\mathrm{Canto}^{6}$, para, posteriormente, efetivar-se a atividade de identificação.

$4^{a}$ fase: Arranjo

Essa é uma das fases mais importantes do processo de organização de um acervo. O arranjo documental serve para que os documentos sejam acessíveis ao uso e para que sejam conhecidos também a sua natureza e o seu conteúdo, pois "o arranjo é o processo de agrupamento dos documentos singulares em unidades significativas, e o agrupamento, em relação significativa, de tais unidades entre si" (SCHELLENBERG, 1980, p. 89).

Nesse sentido, o arranjo dos documentos tem uma relação orgânica entre si, a operação de arranjo:

[...] resume-se à ordenação dos conjuntos documentais remanescentes das eliminações (ditadas pelas tabelas de temporalidade e executadas nos arquivos correntes e intermediários) obedecendo a critérios que respeitem o caráter orgânico dos conjuntos, interna e externamente. Cabe lembrar que se trata de ordenação feita nos arquivos permanentes, quando realmente os conjuntos de documentos produzidos/recolhidos por unidades administrativas e/ou pessoas

${ }^{6}$ Servidora da UFSM (Tradutora/Intérprete), licenciada em Letras Hab. Português/Inglês pela
UFSM, com especialização pela UGF em Ensino de Língua Inglesa e Uso das Novas Tecnologias. 
físicas passam a "conviver" uns com outros, só então passando a ser fundos (BELLOTTO, 2006, p. 136).

O arranjo dos documentos é realizado por meio de definição das séries, subséries, tipos documentais, etc., ou seja, trata-se da distribuição lógica dos documentos de arquivo que compõem o quadro de arranjo.

Bellotto (2006, p. 153) traz a definição de série que a Comissão de Estudo de Terminologia Arquivística da Associação Brasileira de Normas Técnicas estabeleceu no projeto Arquivos: terminologia arquivística: "Designação dada às subdivisões de um fundo que refletem a natureza de sua composição, seja ela estrutural, funcional ou por espécie documental. As séries podem ser dividas em subséries".

Assim, a estrutura do fundo Neusa Carson tem quatorze séries, dentro dessas, algumas subséries e também dossiês, conforme quadro (Quadro 1) abaixo:

\begin{tabular}{|c|c|}
\hline \multicolumn{2}{|r|}{$\begin{array}{l}\text { ESTRUTURA DO QUADRO DE ARRANJO } \\
\text { DO FUNDO DOCUMENTAL NEUSA CARSON }\end{array}$} \\
\hline \multicolumn{2}{|c|}{ SÉRIE 1: Identificação Pessoal e Exercício de Cidadania } \\
\hline & Subsérie 1.1: Documentação Pessoal \\
\hline & Subsérie 1.2: Exercício de Cidadania \\
\hline \multicolumn{2}{|c|}{ SÉRIE 2: Controle de Bens e Patrimônios } \\
\hline \multicolumn{2}{|c|}{ SÉRIE 3: Atividades Profissionais } \\
\hline & Subsérie 3.1: Atividades Docentes \\
\hline & $\begin{array}{l}\text { Subsérie 3.2: Assessoramento prestado para outros cursos da Universidade Federal } \\
\text { de Santa Maria - UFSM }\end{array}$ \\
\hline & \begin{tabular}{l|l} 
Dossiê: Curso de Pós-Graduação em Biodinâmica e Produtividade \\
do Solo da UFSM
\end{tabular} \\
\hline & \begin{tabular}{|l|l|} 
& Dossiê: Curso de Pós-Graduação em Engenharia Rural da UFSM \\
\end{tabular} \\
\hline & Subsérie 3.3: Assessoramento prestado para outras Instituições de Ensino Superior \\
\hline & \begin{tabular}{l|l} 
& $\begin{array}{l}\text { Dossiê: Pontifícia Universidade Católica do Rio Grande do Sul - } \\
\text { PUCRS }\end{array}$ \\
\end{tabular} \\
\hline & Dossiê: Universidade de Brasília \\
\hline & \begin{tabular}{l|l} 
& Dossiê: Território Federal de Roraima \\
\end{tabular} \\
\hline & Subsérie 3.4: Qualificação Profissional \\
\hline & \begin{tabular}{l|l|} 
& Dossiê Mestrado \\
\end{tabular} \\
\hline & Dossiê Doutorado \\
\hline & \begin{tabular}{l|l} 
& Dossiê Pós-Doutorado \\
\end{tabular} \\
\hline & Subsérie 3.5: Atividades de Escriturário \\
\hline & Subsérie 3.6: Homenagens Recebidas \\
\hline \multicolumn{2}{|c|}{ SÉRIE 4: Atividades de Pesquisa, Ensino e Extensão } \\
\hline & Subsérie 4.1: Grupos de Trabalho \\
\hline \multicolumn{2}{|c|}{ SÉRIE 5: Formação Profissional e Acadêmica } \\
\hline & Subsérie 5.1: Ensino Médio (Ginásio) \\
\hline & Subsérie 5.2: Graduação e Pós-Graduação \\
\hline SÉRIE 6: P. & ticipação em Clubes e Associações \\
\hline SÉRIE 7: P & venção de Doenças e Tratamento de Saúde \\
\hline
\end{tabular}




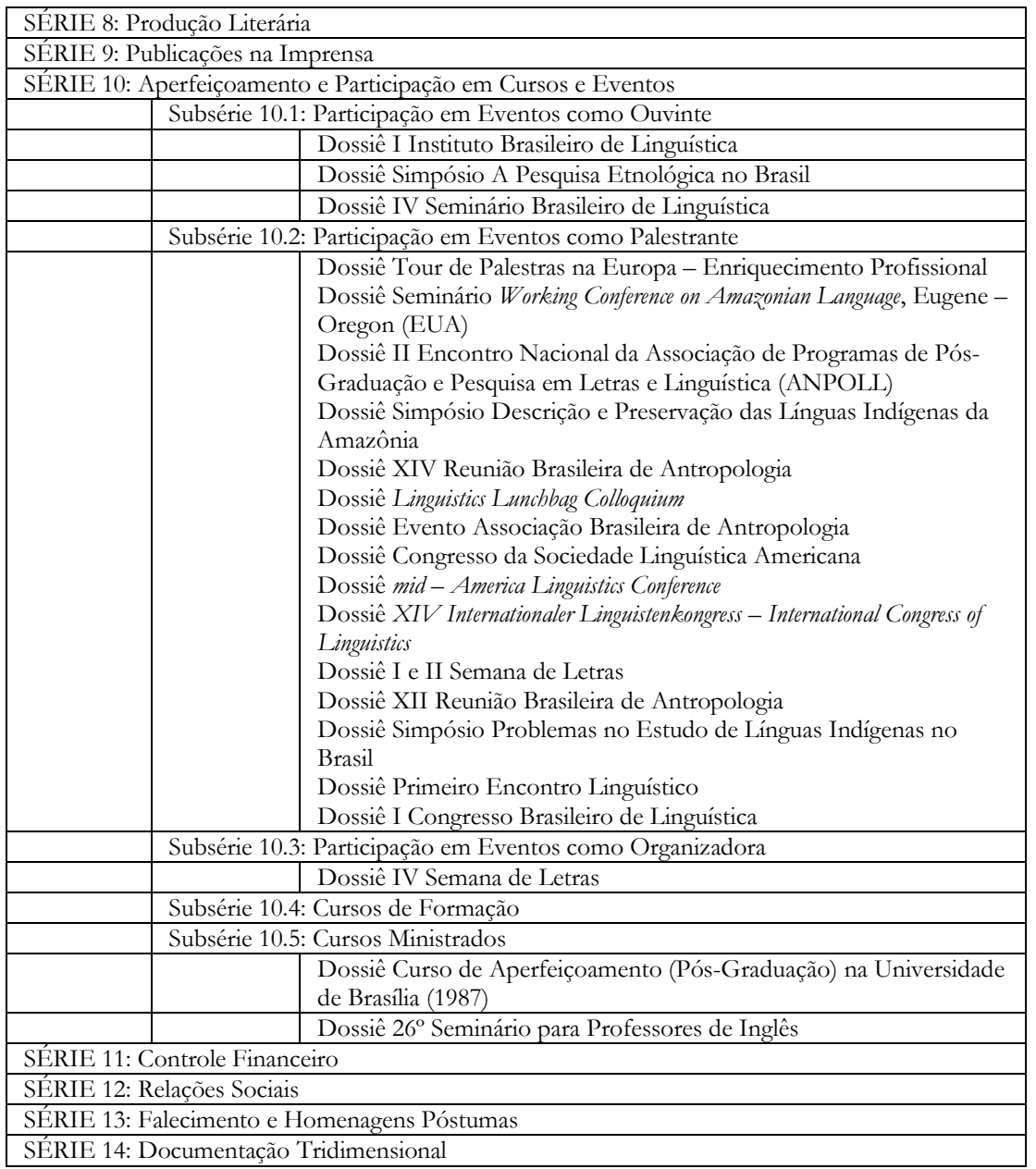

Quadro 1 - Estrutura do quadro de arranjo do Fundo Documental Neusa Carson.

Com o quadro de arranjo documental, apresentam-se mais explicitadas tanto as atividades desempenhadas pela professora Neusa Carson como as ações por ela empreendidas. A documentação do acervo passa a ser demonstrada de forma mais apropriada por meio do arranjo.

\section{$5^{\circ}$ fase: Separação e ordenação dos documentos}


Nessa fase, os documentos são separados fisicamente, de acordo com as suas respectivas séries, subséries e dossiês, assim:

[...] as atividades desenvolvidas no arranjo são de dois tipos: intelectuais e físicas. As intelectuais consistem na análise dos documentos quanto a sua forma, origem funcional e conteúdo. As atividades físicas se referem à colocação dos papéis nas galerias, estantes ou caixas, seu empacotamento, fixação de etiquetas etc. (PAES, 2004, p. 123).

A separação e a ordenação física é uma importante fase do processo de organização do acervo, pois, com isso, será possível visualizar o contexto e todo o conjunto documental do fundo. É nessa etapa também que devem ser escolhidos os melhores materiais de acondicionamento e o mais adequado espaço físico para os documentos.

$6^{\mathrm{a}}$ fase: Descrição dos documentos

A descrição é uma etapa que está em todo o ciclo de vida dos documentos, porém, na documentação de caráter permanente, ela tem um sentido bem mais efetivo. Essa etapa compreende todas as atividades exigidas para a preparação de instrumentos de pesquisas e meios de buscas. O DBTA (2005, p. 67) confirma essa colocação quando afirma que descrição é o conjunto de procedimentos que leva em conta os elementos formais e de conteúdo dos documentos para elaboração de instrumentos de pesquisa. A descrição do acervo será feita a partir da Norma Brasileira de Descrição Arquivística (NOBRADE). A padronização da descrição promovida pela norma torna o instrumento de pesquisa mais consistente e autoexplicativo.

Fazendo a descrição dos documentos, será aplicada toda fundamentação teórica da arquivologia, o conhecimento das características dos documentos arquivísticos e o domínio do instrumental de pesquisa, típico das ciências sociais, para a compreensão do contexto histórico e social no qual o arquivo foi produzido.

$7^{\mathrm{a}}$ etapa: Implantação do Código de Referencia

O Código de referência é elaborado de acordo com a Norma Geral Internacional de Descrição Arquivística - $\operatorname{ISAD}(G)$, destinado a identificar qualquer unidade de descrição. É um código de identificação que permite a ordenação ou localização das unidades de arquivamento.

$8^{a}$ etapa: Elaboração do instrumento de pesquisa 
O objetivo da elaboração do instrumento de pesquisa é divulgar o conteúdo e as características do acervo, bem como tornar a documentação já arranjada e descrita mais acessível ao pesquisador.

Para o fundo documental da professora Neusa Carson, foi escolhido o inventário como instrumento de pesquisa, por melhor se adaptar às características do acervo. O DBTA (2005, p. 109) define inventário como sendo um "instrumento de pesquisa que descreve, sumária ou analiticamente, as unidades de arquivamento de um fundo ou parte dele, cuja apresentação obedece a uma ordenação lógica que poderá refletir ou não a disposição física dos documentos".

$9^{a}$ etapa: Disponibilização para acesso

Após serem finalizadas todas as etapas anteriores do processo de organização do fundo, será possível tornar público e acessível aos pesquisadores o acervo do Fundo Documental Neusa Carson.

\section{Considerações finais}

Os arquivos pessoais vêm sendo cada vez mais valorizados pelos pesquisadores, pois são acervos que se distinguem pela capacidade de apresentar os vínculos do indivíduo com as instituições que fizeram parte, amizades, pesquisas produzidas, etc. Borges enfatiza a importância da utilização dos arquivos pessoais quando cita:

O interesse pelos arquivos pessoais como fontes de pesquisa para a escrita da
história e preservação da memória decorre do fato de a "escrita de si" ali
preservada em suportes variados (cartas, diários, textos autobiográficos, dentro
outros) revelar muito sobre o contexto histórico social das personalidades e não
apenas do indivíduo em si (2012, p. 117).

Apesar de os arquivos pessoais serem dotados de algumas singularidades, o que acaba por diferenciá-los dos arquivos institucionais, isso não impede que a eles possam ser aplicadas regras de organização arquivística. Organizar um fundo documental de um arquivo pessoal requer do profissional um trabalho de pesquisa que não se limita à aplicação de teorias arquivísticas, e sim a dedicação a conhecimentos advindos de outras áreas, como a História, Linguística, Paleografia e a própria área de trabalho do indivíduo a quem pertence o acervo.

O acervo do Fundo Documental Neusa Carson, ainda em processo de organização, tem potencial para realização de inúmeros tipos pesquisas, tanto sobre a vida da professora e pesquisadora, seu legado sobre as línguas 
indígenas, seu principal objeto de estudo, quanto sobre a Linguística produzida nos anos 70 e 80.

\section{REFERÊNCIAS}

ABELLÁS, J. B. Y. Arquivos pessoais, saberes coletivos: A organização da documentação pessoal e pública de cientistas - o caso Hussak. In: SANTOS, P. R. E.; SILVA, M. C . S. M. (Org.). Arquivos pessoais: história, preservação e memória da ciência. Rio de Janeiro: Associação dos Arquivos Brasileiros, p.75-88, 2012.

BELLOTTO, H. L. Arquivos permanentes: tratamento documental. 4. ed. Rio de Janeiro: FGV, 2006.

BORGES, R. S.; MACIEL, L. R. Metodologia de organização de arquivos pessoais: O fundo Virgínia Maria Niemeyer Portocarrero, enfermeira da FEB. In: SANTOS, P. R. E.; SILVA, M. C .S. M. (Org.). Arquivos pessoais: história, preservação e memória da ciência. Rio de Janeiro: Associação dos Arquivos Brasileiros, p.113-136, 2012.

CHAMON, C. S. Inventário do acervo da Escola de Aprendizes Artífices de Minas Gerais: 1910-1943. Belo Horizonte, MG: CEFET-MG, 2011.

DIAS, Juciele Pereira; Rosa, Marluza Terezinha da. Os passos de uma pesquisadora trilhando caminhos da lingüística no sul. In: SCHERER, Amanda; PETRI, Verli; DIAS, Cristiane. Memória em terceira pessoa. Santa Maria: PPGL Editores, 2012 (no prelo).

DBTA - DICIONÁRIO brasileiro de terminologia arquivística. Rio de Janeiro: Arquivo Nacional, 2005.

OLIVIERA, L. H. V. Descrição e Pesquisa: Reflexões em torno dos arquivos pessoais. Rio de Janeiro: Móbile, 2012.

PAES, M. L. Arquivo: Teoria e prática. 3. ed. Rio de Janeiro: FGV, 2004.

ROUSSEAU, J.; COUTURE, C. Os fundamentos da disciplina arquivística. Lisboa: Publicações Dom Quixote, 1998.

SANTOS, P. R. E. Arquivo pessoal, ciência e saúde pública: o arquivo Rostan Soares entre o laboratório, o campo e o gabinete. In: SANTOS, P. R. E.; SILVA, M. C .S. M. (Org.). Arquivos pessoais: história, preservação e memória da ciência. Rio de Janeiro: Associação dos Arquivos Brasileiros, p. 21-50, 2012.

SCHELLENBERG, T. R. Documentos públicos e privados: Arranjo e Descrição. 2. ed. Rio de Janeiro: FGV, 1980.

SILVA, M. C. S. M. Reorganização de fundo: Uma experiência em arquivo pessoal de cientista. In: SANTOS, P. R. E.; SILVA, M. C .S. M. (Org.). Arquivos pessoais: história, preservação e memória da ciência. Rio de Janeiro: Associação dos Arquivos Brasileiros, p. 89-112, 2012. 